\title{
A CIRURGIA BARIÁTRICA EM NOVA FASE NO BRASIL
}

\author{
The new phase of bariatric surgery in Brazil
}

\author{
Almino Cardoso RAMOS ${ }^{1}$, Ivan Cecconello ${ }^{2}$, Osvaldo MALAFAIA ${ }^{3}$ \\ ${ }^{1}$ Presidente da Sociedade Brasileira de Cirurgia Bariátrica e Metabólica; ${ }^{2}$ Presidente do Colégio Brasileiro de Cirurgia Digestiva; ${ }^{3}$ Editor-Chefe do ABCD
}

$A^{c}$ cirurgia bariátrica, em sua maior parte, teve desenvolvimento fora dos meios acadêmicos em quase todas as partes do mundo em que é utilizada. As razões são diversas e fogem ao escopo desse editorial. No Brasil não foi diferente. Anos se passaram com esse aspecto, mas a realidade está mudando. E o que foi que mudou?

Houve compreensão da comunidade que atua na área de que somentesãoválidos os meios emétodos que sejamaplicados com metodologia adequada respaldada por evidências. Desde os remotos tempos de René Descartes, no início do século XVII, sabe-se que não é a impressão, mas sim, a comprovação que nos leva adiante. Uma vez utilizada, a validação dos resultados científicos pode ser divulgada e ser aceita pela comunidade geral e acadêmica como possível verdade científica.

A SBCMB com foco nesse mister, solicitou ao $A B C D$ apoio para engrandecimento científico da cirurgia bariátrica no nosso país. É um grande desafio, pois fazer nossos cirurgiões escreverem..., não é tarefa fácil!

Quando se fala em pesquisa, de um modo geral, logo se pensa em laboratórios com bancadas, animais de experimentação, dedicação de tempo, instrumentos e equipamentos complexos que afugentam os que exercem a cirurgia. Dizem os cirurgiões que não conseguem fazer pesquisa porque estão no centro cirúrgico, não raramente, por horas a fio. Justificam assim a falta de tempo livre para pensar, criar e colocar suas idéias em texto organizado.

Tudo certo, este raciocínio parece estar correto.

Contudo, existe erro de ótica. O que é um laboratório cirúrgico? Pela comparação, ele deve ser cheio de bancadas, mesas, instrumentos com engenharia de ponta. Ele já existe e chama-se: "sala de operações". Por centro de pesquisas entende-se ser fisicamente grande, adequado em espaço, tecnologia e recursos humanos diferenciados com estrutura organizacional e operativa de grande envergadura. Ele já existe e chama-se "centro cirúrgico"!

Então, o que é que precisamos para produzir mais e melhor?

É ter esse entendimento: nosso laboratório é a sala de operações que trabalhamos; nosso centro de pesquisa é o centro cirúrgico que nos recebe; a evolução pós-operatória é nossa enfermaria e ambulatório.

Então o que falta para produzir mais e melhor ciência aplicada? É somente mudar nosso modo de pensar, tanto da parte do profissional como da instituição hospitalar e ser realizada, por outrém, coleta organizada, protocolada e gerenciada para fins acadêmicos. Não precisa o médico assistente realizá-la. Ele precisa, sim, saber o que procurar em seu trabalho e o resto deixar correr como rotina a ser pesquisa em futuro. O cirurgião não muda em nada sua atitude e horas de trabalho. Com isso, ou seja, com a coleta automática dos dados de seu dia-a-dia produzirá dados confiáveis que se acumularão progressiva e prospectivamente, não deixando ir para o ralo as informações que possui e que tanto trabalhou para acontecerem. Mas, se não publicar, ficam elas perdidas e sem valor. Esta sistematização de registro de dados possibilitará melhor acompanhamento dos pacientes, facilitará levantamento de informações para publicação e também permitirá a comparação de resultados entre os diferentes centros identificando a eventual necessidade de correção de metodologia.

Porquê não mudar nossas cabeças? Porquê não divulgar aquilo que nossa experiência entendeu ser melhor para cada paciente? Porquê não maximizar o esforço e o tempo despendidos? Porquê deixar passar a contribuição médica que temos comprovada pelo exercício da profissão?

O Brasil precisa repensar os meios de como conseguir esse mister.

O Colégio Brasileiro de Cirurgia Digestiva e a Sociedade Brasileira de Cirurgia Bariátrica e Metabólica estão ajudando grandemente nossos associados e os cirurgiões brasileiros em geral a conseguirem os meios de publicação. Conseguiram, em parceria, ofertar veículo de qualidade e de visibilidade internacional - que é o $A B C D$ - para difusão de seus conhecimentos. O meio existe. Agora precisamos focar a produção de trabalhos com qualidade, produção esta que já é existente e, às vezes, não percebemos. Temos que cumprir nossa responsabilidade de ser a segunda sociedade de cirurgia bariátrica do mundo.

Não nos esqueçamos:

"Nosso laboratório é nossa sala de operações"! e

"Nosso centro de pesquisas é nosso centro cirúrgico"!

Querem melhor ambiente para pesquisa? Certamente não. O que precisamos é mudar nosso modo de pensar e começar a agir para arrumarmos meios eletrônicos que contabilizem de modo prospectivo a atividade cirúrgica que exercemos.

Vamos pensar juntos! Vamos mostrar mais nossos resultados! Vamos escrever mais!

Assim no futuro, melhoraremos o brilhante cenário que hoje se inicia com este Suplemento, exclusivo da Cirurgia Bariátrica e Metabólica homenageando o Congresso de Brasília. Neste número se demonstra a seriedade e a criatividade do cirurgião brasileiro que, continuando dessa forma, aumentará em breve o respeito da comunidade de nosso País e a internacional com a cirurgia bariátrica brasileira. 